CUPAUAM. 17-1990,267-275

\title{
LA TABULA LOUGEIORUM: UN DOCUMENTO A DEBATE
}

\author{
Alicia Ma CANTO \\ UNIVERSIDAD AUTONOMA DE MADRID
}

\section{Resumen}

En el presente artículo se expresan algunas dudas sobre la autenticidad de la Tabula Lougeiorum.

\section{Summary}

This paper expounds some doubts about the authenticity of the Tabula Lougeiorum.

Las páginas que siguen pretenden dar un avance, necesariamente breve en cuanto que tal, para describir la hipótesis de que la recientemente hallada, y sometida ya a diversos estudios, Tabula Lougeiorum, contiene suficientes elementos como para ser objeto de sospechas en cuanto a su autenticidad. Esta es, pues, una versión restringida del trabajo original, mas extenso y detallado, que será objeto de publicación, espero, dentro de este mismo curso académico (Canto, A. Ma. 1990).

La tabla apareció en circunstancias no bien conocidas en el año 1983. Un químico gallego, J. Cajade, manifestó haberla encontrado casualmente, y sus informaciones discrepan entre "en un pinar a unos $10 \mathrm{Km}$. de Lugo", y "en un radio de no mas de $40 \mathrm{Km}$. de Carbedo del Caurel" (Enríquez, J.A. 1989, 299). Sin informar del hallazgo, y durante una estancia en Londres, el descubridor al parecer la ofreció en venta al Museo Británico. Esta institución contactó con el académico de la Historia Dr. Blanco y con el Depto. de Historia Antigua de Santiago de Compostela para informar de la aparente exportación ilegal de bienes culturales que se pretendía, y la persona en cuestión fue objeto del correspondiente juicio, del que, según parece, ha sido absuelta con posterioridad. La pieza se encuentra en deposito judicial en el Museo Arqueológico de La Coruña.

En el mes de abril de 1987, dentro de las sesiones del Coloquio Internacional sobre Epigrafía Jurídica Romana, celebrado como homenaje a A. D’Ors, el Dr. J. A. Enríquez, filólogo de la U.C. de Madrid, y amigo de la infancia del Sr. Cajade, hizo una presentación de la tabla desde el punto de vista textual y filológico, manteniendo la localización de la misma dentro de territorio gallego 
( $c f$. nota anterior). Fuera de programa, el propio Sr. Cajade mostró diapositivas de la tabla, así como de los análisis metalográficos practicados sobre ella, que demostraban que el bronce "era antiguo", lo que venció casi todas las reticencias de los especialistas presentes en favor de su autenticidad (ya que, a primera vista, la paleografía y su aspecto general, espléndido, contrastaban con su fecha, el año 1 d.C., proporcionada por el consulado de Cayo Cesar y L. Emilio Paulo).

Tras la intervención de ambos, la Srta. D. Dopico, de la Universidad de Santiago, sostuvo que la tabla no procedía de territorio gallego, sino de la zona del Bierzo leonés, y puso de relieve lo mas llamativo del nuevo texto: la mención del conventus Arae Augustae, un convento jurídico de la misma significación y características que los descritos por Plinio, pero éste desconocido y en una fecha augustea. Por lo tanto, se convertía en la prueba fehaciente de que los conventos jurídicos fueron creados por Augusto, como habían venido sosteniendo A. D’Ors (D’Ors, A. 1953, 138) y, más recientemente, G. Alföldy (Alföldy, G. 1983, 518 ss.) y no en épocas claudiana o flavia, como algunos especialistas franceses defendían tiempo atrás (Albertini, E. 1923, 54 ss.; Tranoy, A. 1981, 150 ss.).

Por otra parte, la mención en el texto de.C. Asinio Galo, el influyente amigo de Augusto, como contrayente de un pacto de hospitium y patronatus con una civitas indígena, la de los Lougeios (ya conocidos por la tabla de El Caurel, Lugo), que se manifiestan ex gente Asturum, permitía comprobar una presencia, ignorada hasta ahora, en la Península, de este relevante comes de Augusto, y posterior a su proconsulado en Asia de los años 5-4 a. C. Quizá sea mejor, para comodidad del lector, ofrecer ahora el texto completo de la tabla lucense (Lám. I):

C(aio) Caesare Aug(usti) f(ilio) L(ucio) Aemilio Paullo co(n)s(ulibus). I Ex gente Asturum conventus Arae BAugust(a)e / civitas Lougeiorum hospitium fecit cum / C (aio) Asinio Gallo libereis postereisque eius $/ 6$ eumque liberos posterosque eius sibi libe / reis postereisque suis patronum cooptarunt. / Isque eos in fidem clientelamque suam suo Prumque recepit. / Egerunt legati / Silvanus Clouti / Nobbius Andami.

La tabla ha sido ya objeto de varias presentaciones (Pereira, G. 1984, 1987; Castillo, C. 1989, 279) y de dos publicaciones mas extensas (Dopico, Ma D. 1986 y 1988) donde, evidentemente, se da por buena la pieza, sobre todo a partir de análisis metalográficos realizados por la E.T.S. de Ingenieros Industriales de Vigo cuyo detalle, sin embargo, no ha sido publicado ni por Pereira ni por Dopico. En el número de 1987 de $A E$ (aparecido en el verano de 1990) y bajo el $n^{\circ}$ 561, P. Le Roux apunta aún a las dudas, que ambos compartimos en el citado Coloquio, sobre la posibilidad de la grabación moderna de una pieza antigua, y sobré la que el reciente "caso prenestino" ha vuelto a llamar, estentóreamente, nuestra atención (Guarducci, M. 1980, 412 ss. y 1984-1986, 127).

Se trata, pues, en mi caso al menos, de que no tengo un interés especial por probar la cronología augustea, claudiana o flavia, de la creación de los conventos jurídicos hispanos (e incluso diría que me inclino más bien por la fecha augustea, y hasta concebida a raíz de un "élan" cesariano). Pero sí me creo en la obligación de dar a conocer, si bien sintéticamente ahora, la serie de argumentos por los que pienso que podemos estar ante un falso. Dividiré estos argumentos, para mayor claridad, en "externos" e "internos".

\section{ANOMALIAS EXTERNAS}

1) Mientras el descubridor se niegue a revelar el lugar exacto del hallazgo, de forma que este pueda ser estudiado exhaustivamente desde los métodos arqueológicos, como se ha hecho 


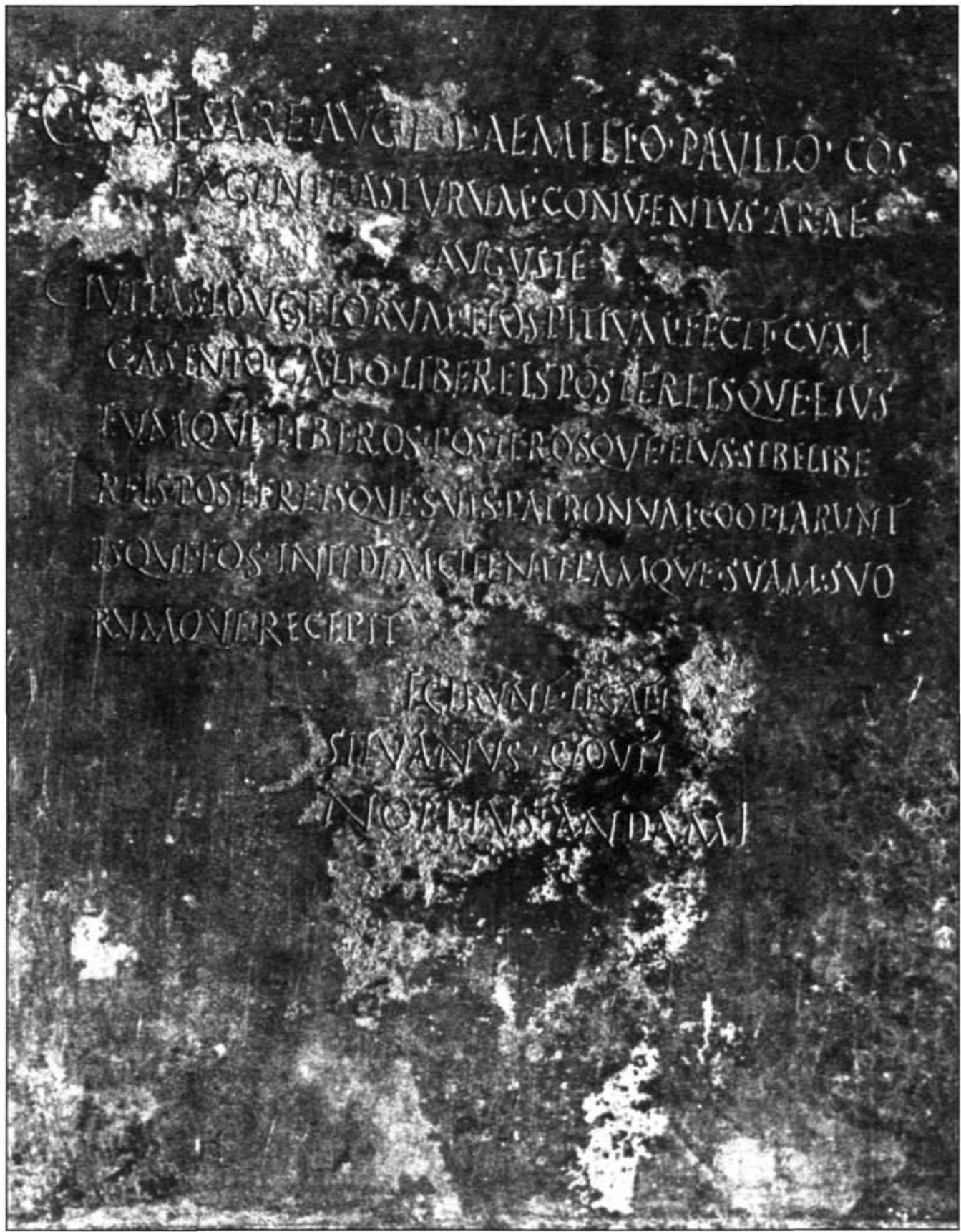

Lámina I. La Tabula Lougeiorum, a partir de una fotografía del Museo Arqueológico Provincial de La Coruña. 
reciente, y modélicamente, con la tabla de Montealegre (Balil, A. y Martín Valls, R., edd. 1988), no parece prudente el aceptar los contenidos de la tabla. Máxime si se pretende reconocer en el Ara Augusta un ejemplo hispano similar nada menos que al Altar de los Ubios germano o al Altar galo de Lyon (Dopico, Ma D. 1988, 56 ss.). No hay que olvidar, además, que el Sr. Cajade ha facilitado dos localizaciones distintas e igualmente imprecisas. Me parece, pues, metodológicamente, una condicio sine qua non el conocer el punto preciso del hallazgo.

2) Tampoco es normal que la pieza se haya sacado de España (sin haber informado a ninguna institución nacional, ni académica ni museística), para su ofrecimiento en venta directa a un museo extranjero. Mas allá de las consideraciones legales o patrióticas, es elemento a tener en cuenta en nuestro juicio.

3) Como he dicho más arriba, los análisis de aleación y otros de la pieza no han sido dados a conocer, por lo que he dispuesto sólo de los resultados ofrecidos en Pamplona por el Sr. Cajade, y de los que tomé nota en su momento. Ellos eran: Fundición directa a molde abierto, con $62 \%$ de cobre, $26 \%$ de plomo, $12 \%$ de estaño y $0.6 \%$ de hierro (sobra un $0.6 \%$, que debe añadirse a alguno de los otros metales). Sin entrar ahora en el detalle, estas proporciones en la aleación de bronce no se corresponden con las usuales en el cambio de era, y hay que esperar a los siglos III y IV d.C. para comprobar esta alta presencia de plomo (de hasta un 30\%: Tylecote, R. F. 1988, 58 ss.) ya que, en etapas anteriores, el bronce contenía más cobre y menos plomo, no pasando éste de un 5 - 10\% de la composición. En cambio, es curiosa la ausencia de Zn. Por decirlo con brevedad, la fundición de monedas, y mas concretamente de "pequeńos bronces" tardíos, daría un resultado analítico parecido al que la tabla de los Lougeios nos presenta. Pero, incluso si otros análisis mas detallados o mejor hechos, apuntaran a un bronce mas común en el período augusteo, ahí esta el caso de la fíbula de Preneste para recordarnos que una pieza antigua puede recibir perfectamente una inscripción moderna. Con los análisis que he manejado (los del descubridor) ni siquiera esto último sería posible.

4) La tabla tiene forma de plancha rectangular, sin huellas de haber tenido un marco, moldurado o simple, y carece asimismo de agujeros de sujeción. G. Pereira ya comentaba esta rareza, asimilándola en la forma a la tabla de Castromao (Orense), del año 132 d.C. (aunque esta moldurada). Por lo tanto, la tabla de los Lougeios no se parece formalmente a ninguna de sus coetáneas, incluso a las más próximas en el espacio: Paredes de Nava ( 2 a.C.), Ronda ( 5 d.C.), Mérida (6 d.C.), Monte Murado, Port. (7 y 9 d.C.), Herrera de Pisuerga (14 d.C.), y El Caurel (28 d.C.), sino a otras del siglo II, y aún a estas no completamente.

5) Las reservas pueden tenerse también respecto de la paleografía. Las letras G, C, R, V, S, A, Q, D y T no pueden compararse con las propias de la época, con una escritura que, en general, suele tener un acusado aspecto aristado y nada de la perfecta ejecución que vemos en la tabla lucense. Incluso en ésta, la ejecución de la misma letra en distintas líneas es de notable diferencia. El abuso de remates y adornos curvos (el caso de las A es particularmente ilustrativo) se puede excluir claramente de una datación en el año $1 \mathrm{~d}$.C. Por el contrario, según he podido comprobar, la comparación es muy satisfactoria con la paleografía de la tabla de Astorga (CIL II 2633), que puede haber sido perfectamente el modelo a copiar ( $c f$. especialmente las M, G, T o sus inconfundibles y cuadrangulares $\mathrm{D}$ ). La tabla de Astorga, que resulta ser también del territorio de los Astures, contiene dos renovaciones de pacto, una del $27 \mathrm{y}$ otra del $152 \mathrm{~d}$.C., pero su grabación responde, como es lógico, a la segunda de estas fechas. Metodológicamente, pues, ¿hay que admitir sin más un paralelo paleográfico entre dos piezas que distan entre sí 150 años? Me parece que no sería prudente. 


\section{ANOMALIAS INTERNAS}

6) La presentación sintáctica del texto en su comienzo: la secuencia "determinativo en ablativo / determinativo en genitivo / sujeto", como se da en las lín. 2-4 de la tabla, no es la normal en los pactos de hospitalidad conocidos ( $c f$. el útil catálogo que da Dopico, $\mathrm{M}^{\mathrm{a}} \mathrm{D}$. 1988, 67 ss.): ex gente Asturum, conventus Arae Augustae, civitas Lougeiorum. El sujeto del pacto debería sin duda haber ido en primer lugar, seguido de sus determinativos étnico y administrativo.

7) La expresión conventus Arae Augustae tampoco es aceptable, ya que habría que esperar Araugustani, como en los ejemplos mas asimilables : Caesaraugustanus, Bracaraugustanus. Y, por otro lado, las definiciones de los conventos no suelen hacerse por referencia directa a la ciudad capital, sino en forma adjetivada. Un hipotético conventus Gadium o un conventus Tarraconis nos producirían similar inquietud.

8) La definición de los Astures como una gens no encaja con la documentación textual o epigráfica que tenemos hasta ahora. Si Pésicos, Zoelas, Lougeios, Gigurros o los recentísimamente venidos a la luz Gilúrnigos (excavaciones de C. Fernandez Ochoa en Gijón, en el verano de 1990, que ella publicara en breve) son, en el lenguaje de Plinio, populi, y en el epigráfico gentes, pertenecientes a la etnia astur, de categoría superior, los Astures mismos no pueden ser denominados gens.

No voy a entrar ahora, por la brevedad a la que apelo, en la amplia bibliografía y problemática de los conceptos etno-territoriales en la zona Noroeste hispana, pero sí adelanto mi idea de que la definición de los Astures puede ser la de uno de los grandes genera hominum Hispanorum, si aceptamos el paralelo que da Plinio en $\mathrm{NH}$ III, 4, 99, donde describe a los cinco genera hominum Germanorum. El orden jerárquico de las entidades sería, tal como lo veo, genus / populus, gens/gentilitas / genitivos de plural. Cada gens se reparte en varios núcleos de habitación (castella o civitates en el sentido urbano) ocupados por gentilitates y familiae. Las familias (los genitivos de plural) vendrían a equivaler a las gentes romanas. De cualquier forma, el debate sobre todas estas cuestiones sigue por completo vigente, y se relaciona estrechamente con la polémica sobre el signo $\supset$ en los epígrafes ( $c f$. últimamente Studia Palaleohispanica 1987 y Beltrán, F. 1988). ¿C(astellum), c(enturia), c(ensus), g(entilitas)? Creo que no se resolverá mientras se persista en analizar globalmente las áreas y las épocas tan diversas en que aparece el célebre signo. Pero, en lo que en estas líneas importa, la definición de los Astures como una simple gens es más que discutible, al menos en lo que se refiere al siglo I d.C. (y usar fuentes diacrónicas para ello puede ser motivo de confusión, puesto que la misma tabla de Astorga revela un cambio evidente en los conceptos, si no estructurales al menos terminológicos, entre el siglo I y el II d.C.).

9) La referencia habitual del sujeto colectivo, en los pactos de hospitalidad, es a la provincia: así, en Peñalba (Clunienses ex Hispania Citeriore), Badalona (Baetulonenses ex H. C.), Mulva (cum senatu populoque Muniguensi ex Hispania Ulteriore), Castromao (Coelerni...ex Hispania Citeriore) Themetra (civitas Themetra ex Africa), Gurza (civitas Gurzensis ex Africa), etc. De ahí que la referencia de la pequeña civitas Lougeiorum a su convento jurídico (expresado éste además, como ya dije, en forma no adjetivada) y no a su provincia, resulte extraña, máxime cuando nos movemos teóricamente en una fecha, el año 1 d.C., en que está solo comenzando a avanzarse en la reorganización administrativa peninsular.

10) En todos los conventos jurídicos citados por el polígrafo, que ascienden a 27 (y aplicados, como se sabe, aunque no por qué motivos, sólo en cinco provincias), hay una auténtica ciudad, que es la capital del mismo y la que le da nombre. El hecho de que un altar indígena sea 
“capital provisional" de un convento jurídico augusteo (Dopico, Ma D. 1988, 56 ss.) no tiene paralelos y, para comenzar, la ausencia de un gran centro de culto indígena previo parece probada por las exploraciones arqueológicas en Astorga (Mañanes, T. 1983, 6). Con ello, los paralelos del Ara de los Ubios o del Altar de los galos en Lyon no serían, por desgracia, de aplicación aquí. Por otra parte, Roma tenía harta costumbre de agere in castreis en Hispania durante la República, y no se ve por qué la excepción, sugerida por D. Dopico, de, durante la construcción de Asturica Augusta, utilizar el Ara Augusta como capital provisional. Máxime si, creyendo a Ptolomeo (2, 6, 35 : cuando dice que el lugar de Asturica habla sido capital de los Astures ámacos), admitiéramos la existencia de cierta infraestructura urbana previa (que Roma, en todo caso, tampoco necesitaba).

11) Un lugar de culto indígena de esta relevancia, que mereciera el aprovechamiento por Roma como centro religioso, administrativo y jurídico, pienso que hubiera dejado rastro en la toponimia o en las vías de comunicación, lo que no se da (Roldán, J. M. 1973, 73, 75 y glosario) ya que, de no estar bajo Astorga, debería encontrarse en su entorno. Y el dios o dioses que recibieran culto en él no hubieran dejado de perpetuarse en la producción epigráfica de época romana, como ocurre, por ejemplo, con los grandes santuarios de Endovélico o Ataecina en el SO. peninsular. Parece no ser tampoco el caso. Ello no quiere decir que no hubiera arae Augustae, y no sólo las nunca halladas, dedicación de L. Sestio Quirinal, sino varias mas, erigidas en distintos puntos del escenario de las últimas campañas de Augusto (cf. recientemente Rodríguez Bordallo, R. y Ríos Graña, A. Ma 1985), pero de ahí a que una de ellas pudiera ser capital de un convento, media una buena distancia.

12) Quedan algunas cuestiones menores, como la falta de reciprocidad en la parte de la tabla dedicada al patronato, o el cambio de número en la expresión verbal, pues mientras en la lín. 4 tenemos un único sujeto singular: civitas ... fecit, en la 7 , y aún dentro de la misma frase, el verbo cambia a plural, cooptarunt, sin disponer de un nuevo sujeto. $\mathrm{O}$ el hecho de que en el nombre del segundo de los legados haya dudas entre Nobbivs y Noppivs (Enríquez, J. M. 1989, 300 y Castillo, C. ibid. 279), mientras el descubridor (en su propia transcripción, ofrecida en Pamplona), se decidía por Nollivs. Mirado el lugar con aumentos, es curioso comprobar que un primitivo Nollivs grabado ha sido aparentemente corregido a Nobbivs. La lectura de C. Castillo, evidentemente, se basaba en la fuerza de los travesaños inferiores de las L, que daban lugar a pensar en dos P. Nollivs sería, en cambio, la lectio difficilior. Otra anomalía más de las que adornan a este extraño bronce...

Termino ya, porque creo haber aportado casi todas mis dudas sobre este documento. Muchos países envidian quizá a España la extraordinaria cantidad de documentos jurídicos romanos que nuestros suelos devuelven a la Historia, especialmente en los últimos diez años. Puede que ello se deba al auge del descontrol en el uso de detectores de metales en nuestro país, lo que no es precisamente un motivo de honra. Pero, sabiéndolo como nosotros lo sabemos, y ante casos como el de la fíbula de Preneste, no debemos admitir documentos de esta clase si no media antes una investigación arqueológica exhaustiva, que nos de unas mínimas garantías sobre el yacimiento del que procede, y máxime cuando, como en este caso, tenemos un testigo directo. ¿Que duda puede caber sobre el interés científico de poder excavar un centro religioso indígena y romano y capital de un convento augusteo? Y ¿ como aceptar, si ello se nos niega, su existencia? Hay, pues, en este caso de la tabula Lougeiorum, una conclusión metódica importante.

No necesito casi decir que es mi impresión que podemos encontrarnos ante un falso. Un falso que pudo no ser hecho en nuestros días, sino en otras épocas. El posible modelo, la tabla 
de Astorga, ya era conocido de antiguo y figuraba recogido tanto en el CIL como en las ILS, aunque el conocimiento de los Lougei, sólo a través de la tabla de El Caurel, es mas reciente, y parece situar un terminus ante quem non en los años sesenta. No voy a entrar a dilucidarlo, y cada cual es muy libre de hacer sus propias interpretaciones. Los datos precisos para ello ya están descritos. No cabe más solución sino que el $\mathrm{Sr}$. Cajade indique el lugar preciso de su hallazgo. Si aparece el Ara Augusta, con toda la epigrafía y restos arqueológicos pre- y augusteos que de ella cabría esperar, siempre estaré bien avenida a rectificar y admirarme de las sorpresas que aún nos depare la administración romana. Pero en tanto ello no ocurra, no veo posibles variaciones a las sospechas que la tabla me suscita. Los conventos jurídicos pudieron ser creación augustea, en la línea de lo defendido, especialmente, por D’Ors y Alföldy, pero me temo que la respuesta a esa interrogante no se encuentre en la tabula Lougeiorum...

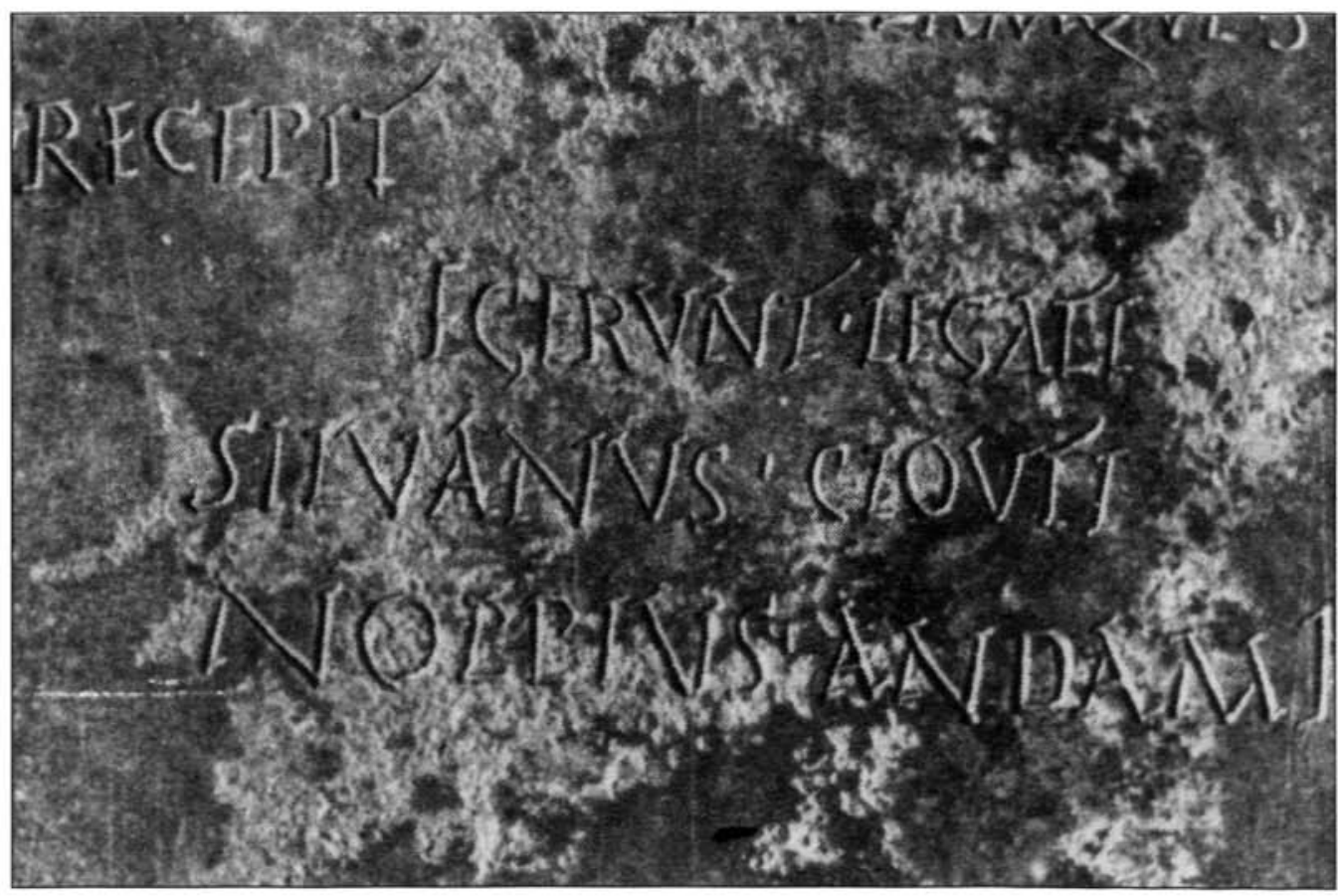

Lámina II.- Detalle de la palabra Nollivs/Noppivs, en la última linea de la tabla de los Lougei. 


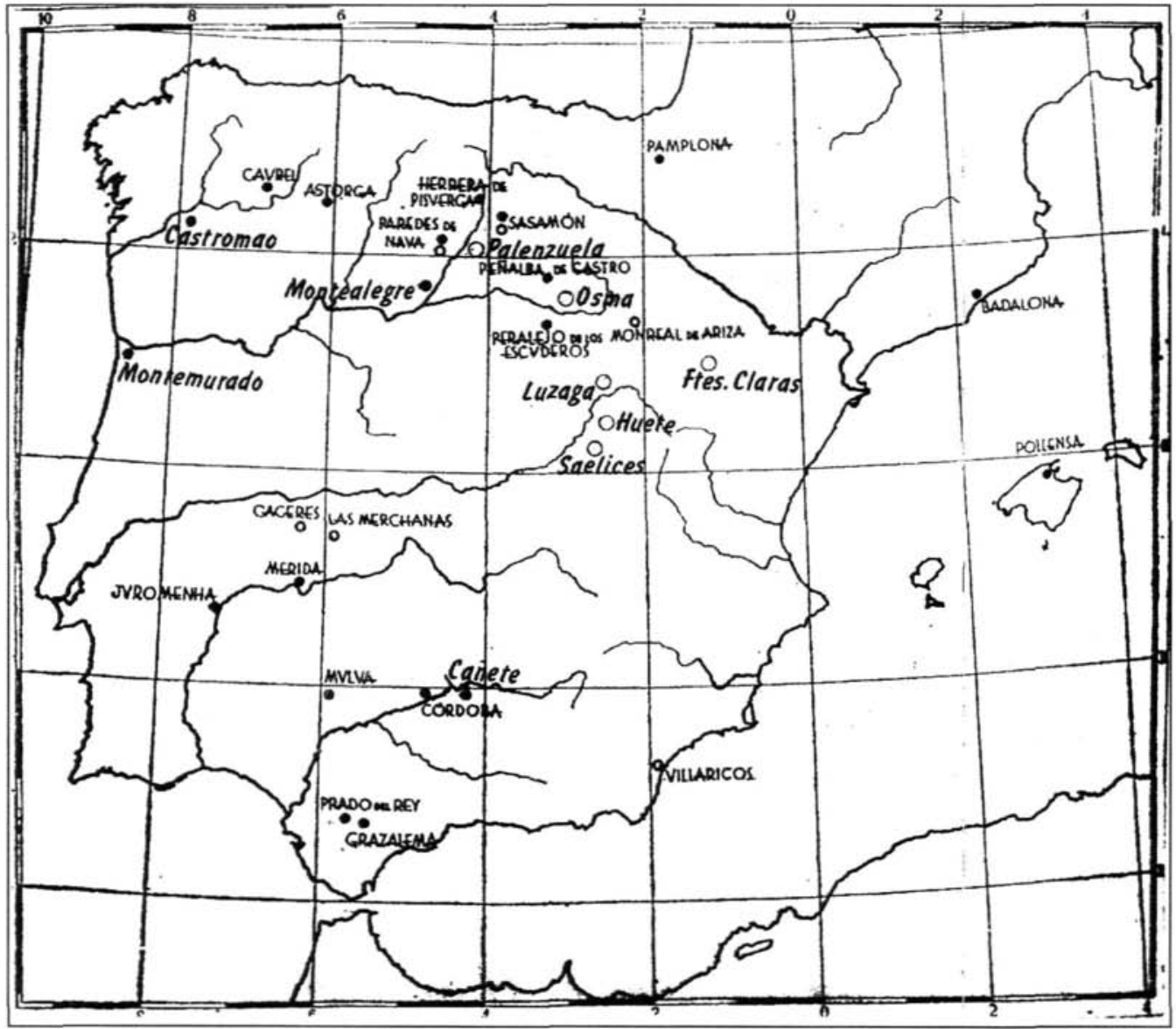

Figura 1

[Me ha parecido útil aprovechar esta ocasión para actualizar, en la Fig. 1, el mapa de distribución de las tesserae y tabulae de hospitalidad aparecidas en la Península, utilizando como partida el que ofrecía A. García y Bellido en su trabajo de 1966 (García y Bellido 1966), a cuya inconfundible letra añado, en cursiva, los hallazgos posteriores a aquel año, mas tres celtibéricas que hacen alusión a la hospitalidad (gortica). Como el decía, la inclusión en el catálogo de las teseras de hospitalidad de texto breve y datación incierta "estadística y geográficamente tiene su importancia para la historia de esta institución en España.” (p. 159)]. 


\section{BIBLIOGRAFIA}

ARIAS et al. 1979: Arias Vilas, F., Le Roux, P., Tranoy, A., Inscriptions romaines de la province de Lugo, París.

AlBerTINI, E. 1923. Les divisions administratives de l'Espagne romaine, París.

AlFÖLDY, G. 1983. "Zur Geschichte von Asturia et Gallaecia. Bemerkungen zu Alain Tranoy, La Galice romaine". Germania 61,511 ss.

Balil, A. y Martin Valls, edd. 1988: Tessera hospitalis de Montealegre de Campos (Valladolid). Estudio y contexto arqueológico, Valladolid.

Beltran, F. 1988: "Un espejismo historiográfico. Las 'organizaciones gentilicias' hispanas", Actas I Congreso Peninsular de Historia Antigua, Santiago de Compostela, vol. II, 197 ss.

Canto, A. Ma , 1990: “¿Conventus Arae Augustae?”, en Homenaje a José Ma Blázquez, U. C. de Madrid, en prensa.

CASTILlo, C. 1989. "Epigrafía jurídica romana en el último decenio: Epoca imperial", Novedades de Epigrafia juridica romana en el último decenio (Actas del Coloquio Internacional de la A.I.E.G.L., Pamplona 1987), Pamplona, 279.

Dopico, Ma D. 1986: "Los conventus iuridici. Origen, cronología y naturaleza histórica”, Gerión 4 (apar. en 1987), 265 ss.

... 1988. La Tabula Lougeiorum. Estudios sobre la implantación romana en Hispania (Anejos de Veleia 5), Vitoria-Gasteiz.

ENRIQUEZ, J. A. 1989. “Una nueva tabula patronatus", ibid. 299 ss.

Garcia Bellido, A. 1966. "Tessera hospitalis del ańo 14 de la era, hallada en Herrera de Pisuerga", BRAH 159, 149 ss.

GuARDUCCI, M. 1980. "La cosidetta fibula prenestina: Antiquari, eruditi e falsari nella Roma dell 'Ottocento", Mem. Accad. Lincei, ser. 8, 24, 412 ss.

... 1984-86. “Nuovi elementi...", ibid. 28, 127 ss .

MAÑANES, T. 1982. Epigrafia y numismática de Astorga y su entorno, Salamanca.

ORS, A.D'. 1953. Epigrafia juridica de la España Romana, Madrid.

Pereira, G. 1984. "Nueva tabula patronatus del Noroeste de Hispania”, Actas II Congreso Gallego de Estudios Clásicos, en prensa .

... 1987. "Nueva tabula patronatus del Noroeste de Hispania", Studia Palaeohispanica (Anejos de Veleia 2-3) Vitoria Gasteiz, 299 ss.

RoldAN, J. M. 1973. Itineraria Hispana, Madrid.

RODRIgUez BORDALlo, R .y Rios GRAÑA, A. 1985. "El simbolismo, la localización y el número de las Aras Sestianas”, Actas del II Coloquio Galaico-Minhoto, Santiago de Compostela, vol. I, 255 ss.

Studia Palaeohispanica, Actas del IV Coloquio Internacional de Lenguas y Culturas paleohispánicas, Vitoria 6-10 Mayo 1985), Vitoria Gasteiz, Anejos de Veleia 2-3, 1987.

Tranoy, A. 1981. La Galice romaine, París.

TYLECOTE, R. 1988. A History of Metallurgy, Londres (4a ed. de 1976). 